\title{
The Influence of Firm Training Design on the Communicatin Ability of Employees
}

\author{
Zheling Wang ${ }^{1, a}$
}

\author{
${ }^{1}$ Henan University of Technology \\ a201820020314@stu.haut.edu.cn
}

\begin{abstract}
Influenced by COVID-19, many daily activities of enterprises turn to online mode. The Internet facilitates people's communication, but at the same time, it also provides an invisible barrier for communication. In this case, it is necessary to explore the influence of communication training course design on employees' communication ability and work performance, so that enterprises can realize the importance of communication training design.
\end{abstract}

Keywords : Training course design, communication skills, work performance.

\section{INTRODUCTION}

Communication is a basic problem that social and economic activities and individuals often encounter in social life. The real connotation of enterprise management process also lies in the effective communication between external and internal.

At present, more and more enterprises begin to realize the importance of training, and are willing to design training courses in enterprises to improve the ability of employees, and ultimately achieve the purpose of improving work performance. However, when enterprises design training courses, it is easy to ignore the importance of designing communication training courses.

Nowadays, under the backdrop of the development of the Internet and the impact of COVID-19. Many enterprises' daily activities are transformed from offline to online. The communication mode of enterprises is also changed from face-to-face communication to online social media. Compared with the offline communication, the intimacy of online communication is lower, and the oral expression ability and body language communication ability of employees are affected.[1] To improve this situation, it is necessary to design communication training courses to improve the communication ability of employees and make them adapt to the current communication mode. However, many enterprises have not yet realized the influence of designing communication training courses on employees' communication ability and job performance, and ignore the training design of employees' communication ability.
Therefore, this paper takes COVID-19's influence, the rapid development of the Internet and the gradual change of enterprise communication mode as an opportunity to make the enterprises fully aware of the significant impact of communication training design on the communication ability and work performance of employees, so as to promote the design of communication training for enterprises and help enterprises develop continuously.

\section{THEORY AND HYPOTHESIS}

\subsection{Employee training design and job performance}

Employee training refers to any activity of imparting knowledge and skills required by work to employees, as well as any form of education related to work .[2]

In 2005, Arnold and other scholars proposed that training should be based on the analysis of needs; And the design of training must meet the needs. Only in this way can training be effective.[3] Wang Songxian (2006) thinks that the training procedure of on-the-job personnel should include the investigation and analysis of training needs, the design of training scheme, the operation of training implementation and the evaluation of training benefits. The design and content development of training courses are the key to the training work, which determines the success or failure of the training work and the quality of the effect. It can be seen that the effect of training is influenced by the motivation of training and the rationality of training design.[4] 
As for the definition of job performance, Bernardin defines it as the behavior that the result of an individual is related to the strategic goal of the organization in which the individual works.[5] This paper mainly adopts the two-dimensional model of job performance proposed by Borman and motowidlo in 1993, which considers that performance includes task performance and relationship performance. Among them, task performance refers to the performance related to specific job and work content, that is, the performance completion specified in job description. Relational performance refers to the behavior that employees voluntarily abide by, or the behavior related to non-specific work proficiency that employees consciously abide by, although there are no explicit provisions, which enterprises hope employees can do but cannot require. It plays a positive role in promoting organizational performance and personal performance, and is the sum of a series of behaviors conducive to the overall performance of the organization.

In 1996, Hiltrop believed that the transformation of training is a dynamic process with high uncertainty. To enable employees to adapt to the rapidly changing environment with high level of skills, it is necessary to continuously invest in training. At the same time, due to the greater uncertainty of people, only effective training design can help to improve work performance.[6]

In addition, Arnold pointed out that employees with skills training are more proficient in performing tasks and can complete the work with high quality. In 2002, Warr proposed that the success of knowledge transfer can improve work performance, which is influenced by personal characteristics, organizational support and the rationality of training content.[7]

Therefore, the following hypotheses are put forward:

$\mathrm{H} 1$ :Enterprise training design has a positive impact on job performance.

\subsection{Training course design and staff communication ability}

In the late 20th century, many scholars defined communication ability. In 1974, Brochller and Ken defined it as the ability to connect with others, and to gradually and effectively build relationships with others. This definition makes people realize that communication ability should be the ability of both sides to interact. In 1984, Spitzberg put forward that communication ability is a kind of behavior ability in a specific situation. [8]In 1988, he defined communication ability. He believed that the communication with ability should be effective in the result, and the behavior in the process should be appropriate. He emphasized effective communication and appropriate communication.[9] Foote and Cottrell defined communication ability as the ability to communicate effectively in 1995.[10]

Li Heling, Hu Ningna and Ran Li pointed out that scenario simulation training is helpful to improve the interpersonal communication ability between nurses and patients. Wang Zhaoqin also pointed out: after the communication skills training for nurses, when communicating with patients, nurses' dressing, environment introduction, personnel introduction, data checking and convenience measures were improved .[11]

It can be seen that after the communication training, the effectiveness of the results and appropriateness of the process of communication between nurses and patients have been improved.

Therefore, the following hypotheses are put forward:

$\mathrm{H} 2$ :Enterprise training design have a positive impact on employees' communication ability.

\subsection{Employee communication ability and job performance}

Carol Ann Boye pointed out in 2003 that communication ability, innovation ability and learning ability all play a positive role in improving organizational performance.[12] In 2004, Zhang Huichen pointed out in his article: the continuous performance communication between managers and employees is the most direct link of performance management. Without it, performance management can not be successful. [13] Michal L.Boorom,Jerry R.Goolsby,Rosemary P.Ramsey (1998) studied the influence of communication skills on adaptive sales and sales performance. [14] He evaluated the sales staff's communication ability from three dimensions of attention, perception and reaction, and through two stages of communication, which are: the degree of overcoming the fear of communication before communication and the degree of involvement in the communication process. The positive effect of communication ability on adaptive sales and sales performance is confirmed by empirical analysis.

Therefore, the following hypotheses are put forward:

H3:Employee communication ability has a positive impact on job performance.

The research model is shown in Figure1.

Task performance

Relationship performance

Figure 1. Theoretical model of training curriculum design, communication ability and job performance 


\section{RESEARCH METHOD}

This paper mainly uses the method of literature research.

\subsection{Sample determination}

This paper uses the data of Zhong Dingguo and Liu Jie in 2014, taking the employees of five high-tech enterprises in Xi'an, Shenzhen and Guiyang as the research objects. A total of 270 questionnaires were distributed, and 237 valid questionnaires were collected, with an effective recovery rate of $87.7 \%$. In terms of age, $89.2 \%$ of the respondents were under 30 years old; In terms of educational level, $99 \%$ of them have college degree or above; In terms of monthly income, 1501-5000 accounts for $76.6 \%$ of the total.[2]

This paper also uses the research data of Li Heling, Hu Ningna and Ran Li in 2006. 79 nurses were selected by stratified sampling method and randomly divided into observation group (40 nurses) and control group (39 nurses). The nurses in the observation group were given scenario simulation training in the routine nursing work, while the nurses in the control group were not given scenario simulation training in the routine nursing work. There was no significant difference in age, education background, length of service and professional title between the two groups $(\mathrm{P}>0.05)$.[15]

At the same time, this paper also uses Liu Xi's survey data in 2008, which selects multinational companies investing in Changsha as the survey sample. By means of on-the-spot questionnaire, 200 questionnaires are distributed and 126 are effectively recovered. The effective recovery rate of the questionnaire is $63 \%$ Hitachi automotive appliances (Changsha) and Electrolux (Changsha) appliance sales staff in three multinational companies were investigated. According to the distribution of the survey samples, $55.6 \%$ of the respondents are 25-35 years old. In terms of marriage, the proportion of married people is $25.4 \%$ higher than that of unmarried people. In terms of educational background, most of them have bachelor's degree or college degree. In terms of work experience, about half of the respondents have more than four years of work experience and about half have less than four years of work experience. The sample structure is reasonable and the respondents are highly representative.[16]

\subsection{Data collection and processing}

Zhong Dingguo and Liu Jie measured the variables. They used the Likert7 point scoring method to measure all the items. 1 of them expressed strong disagreement. 7 agreed very much. The respondents could choose according to their own conditions.
For the measurement of staff training, it adopts the scale of staff training proposed by Cagri\&Os-man [17], and makes some adjustments according to the actual situation. The training intention includes four items, such as participating in more training projects as far as possible; Willing to take advantage of various learning and development opportunities, etc; Training income includes 7 items, such as training is helpful to personal development; Help to increase promotion opportunities, etc; Training opportunities include three items, such as understanding the type and scale of training to be conducted in the future; Superior support includes four items, such as manager's enthusiastic support for employees to participate in training; Will not hesitate to tell the manager the need for specific areas of training. Cronbach's $\alpha$ The coefficient is 0.895 , and the four dimensions of Cronbach's $\alpha$ The coefficients were 0.783 , $0.727,0.834$ and 0.793 , respectively. Therefore, the scale has a good effect.

Li Heling, Hu Ningna and Ran Li used the patient to nurse communication ability evaluation form and nurse communication ability self-evaluation form to evaluate the effect of three-month scenario simulation training. Among them, the nurse communication ability evaluation form was filled out by 98 patients who had been hospitalized for more than one month in six wards.

Liu Xiyuan first developed and designed the questionnaire. Communication ability was taken from the scale used by Michal L.Boorom,Jerry R.Goolsby and Rosemary P.Ramsey (1998). Communication ability was considered from the three dimensions of concentration, perception and responsiveness. Sales performance was based on his own summary of previous studies on personal sales performance. Secondly, combined with the actual situation, the content of the scale was purified and revised. After purification, the communication ability scale as a whole was improved $\alpha$ The coefficient is 0.863 , and the overall scale of sales performance is stable $\alpha$ The coefficient is 0.803 , which shows that the reliability of the scale is good. Finally, factor analysis was carried out on the purified scale, and the factor reliability was tested.

\section{RESEARCH RESULTS}

Zhong Dingguo and Liu Jie oi-used correlation analysis and regression analysis methods to analyze the data, and used SPSS17.0 to process the data, and made correlation analysis on the research variables to observe whether the correlation of the variables is consistent with the hypothesis. The conclusions are shown in Table 1:

It can be concluded from Table 1 that employee training has a significant positive correlation with task performance and relationship performance, and the results in Table 1 show that the research hypothesis $\mathrm{H} 1$ has been preliminarily verified. 
Tab.1 The means,standard deviations and correlation coefficients of the varuables $(n=237)$

\begin{tabular}{|c|c|c|c|c|c|c|}
\hline Variable & Mean & Standard deviation & 1 & 2 & 3 & 4 \\
\hline Staff training & 5.255 & 0.934 & 1 & & & \\
\hline Task performance & 5.678 & 0.979 & $0.481^{* *}$ & 1 & & \\
\hline $\begin{array}{c}\text { Relationship } \\
\text { performance }\end{array}$ & 5.829 & 0.979 & $0.623^{* *}$ & $0.635^{\star *}$ & 1 & \\
\hline
\end{tabular}

Note:*** means $\mathrm{P}<0.001, * *$ means $\mathrm{P}<0.01, *$ means $\mathrm{P}<0.05$

Tab. 2 Patients' evaluation of nurses' communication ability

\begin{tabular}{|c|c|c|c|c|c|c|c|c|c|}
\hline & & \multicolumn{2}{|c|}{ Good form } & \multicolumn{2}{|c|}{ Understanding } & \multicolumn{2}{|c|}{ Have affinity } & \multicolumn{2}{|c|}{$\begin{array}{c}\text { Strong language } \\
\text { kill }\end{array}$} \\
\hline Group & $\begin{array}{l}\text { Number of } \\
\text { people }\end{array}$ & $n$ & $\%$ & $\mathrm{n}$ & $\%$ & $\mathrm{n}$ & $\%$ & $\mathrm{n}$ & $\%$ \\
\hline $\begin{array}{c}\text { Observation } \\
\text { Group }\end{array}$ & 40 & 35 & 87.5 & 29 & 72.5 & 30 & 75.0 & 36 & 90.0 \\
\hline $\begin{array}{l}\text { Control } \\
\text { Group }\end{array}$ & 39 & 21 & 53.8 & 12 & 30.8 & 15 & 38.5 & 23 & 59.0 \\
\hline$x^{2}$ value & & \multicolumn{2}{|c|}{18.20} & \multicolumn{2}{|c|}{17.80} & \multicolumn{2}{|c|}{19.32} & \multicolumn{2}{|c|}{20.56} \\
\hline Pvalue & & \multicolumn{2}{|c|}{0.008} & \multicolumn{2}{|c|}{0.009} & \multicolumn{2}{|c|}{0.007} & \multicolumn{2}{|c|}{0.006} \\
\hline
\end{tabular}

Tab.3 Self evaluation of nurses' communication ability

\begin{tabular}{|c|c|c|c|c|c|c|c|c|c|}
\hline & & $\begin{array}{l}\text { Enh } \\
\text { ada }\end{array}$ & & $\begin{array}{l}\text { Can } \\
\text { dea }\end{array}$ & al with & $\begin{array}{l}\text { Sel } \\
\text { con } \\
\text { Imp }\end{array}$ & & $\begin{array}{l}\text { Eas } \\
\text { acc } \\
\text { pati }\end{array}$ & $\begin{array}{l}\text { be } \\
d \quad \text { by }\end{array}$ \\
\hline Group & $\begin{array}{c}\text { Number of } \\
\text { people }\end{array}$ & $\mathrm{n}$ & $\%$ & $\mathrm{n}$ & $\%$ & $\mathrm{n}$ & $\%$ & $\mathrm{n}$ & $\%$ \\
\hline $\begin{array}{l}\text { Observation } \\
\text { Group }\end{array}$ & 40 & 37 & 92.5 & 34 & 85.0 & 30 & 75.0 & 33 & 82.5 \\
\hline $\begin{array}{l}\text { Control } \\
\text { Group }\end{array}$ & 39 & 18 & 46.2 & 20 & 51.3 & 15 & 38.5 & 20 & 51.3 \\
\hline$x^{2}$ value & & 20 & & 19.2 & & 16. & & 18. & \\
\hline Pvalue & & 0.0 & & 0.00 & & 0.0 & & 0.0 & \\
\hline
\end{tabular}

H1 shows that firm training has a positive effect on job performance. If the enterprise can design reasonable and effective training courses for employees according to the needs, so that employees can feel the strong support of the enterprise for employees and the benefits that the training courses can bring, the training can stimulate the enthusiasm of employees, make them work harder to complete the task, and improve the relationship between them and colleagues, so as to achieve the effect of improving work performance.

Li Heling, Hu Ningna and Ran Li used SAS8.0 statistical software for data processing, and used $x^{2}$ to test the counting data. The conclusions are shown in Table 2 and Table 3:

From Table 2 and Table 3, it can be concluded that employee training has a positive impact on communication ability, and the results show that the 
research hypothesis $\mathrm{H} 2$ has been preliminarily verified.

$\mathrm{H} 2$ shows that enterprise training courses design have a positive impact on employees' communication ability. If the enterprise can design the corresponding communication training course for the purpose of improving the communication ability according to its own actual situation, then in this case, the employees can not only improve their own quality and self-confidence, but also improve their communication ability, interact with others better and establish a good relationship with others more quickly.

Liu Xiyuan used SPSS13.0 to analyze the correlation between communication ability and sales performance of sales staff in multinational companies, and found that although there was no significant positive correlation between communication focus and sales performance, there was a significant positive correlation between communication reaction and communication perception and sales performance. The results are shown in Table 4:

Tab. 4 Correlation Analysis of communication ability and sales performance

\begin{tabular}{|l|l|l|l|l|}
\hline \multicolumn{2}{|l|}{} & $\begin{array}{l}\text { Communication } \\
\text { response }\end{array}$ & $\begin{array}{l}\text { Communication } \\
\text { perception }\end{array}$ & Communication focus \\
\hline Sales performance & $\begin{array}{l}\text { correlation } \\
\text { coefficient }\end{array}$ & $0.557^{* *}$ & $0.460^{\star *}$ & 0.033 \\
\cline { 2 - 5 } & Significance & 0.000 & 0.000 & 0.771 \\
\hline
\end{tabular}

Note: $* *$ in the table indicates a significant correlation at the level of 0.01

It is concluded that "communication reaction" is positively correlated with "communication perception" and sales performance, which preliminarily verifies the hypothesis $\mathrm{H} 3$.

H3 indicates that communication ability has a positive effect on job performance. The improvement of employees' communication ability can make employees better interact with others and establish a relationship with others more quickly and effectively, which is conducive to the improvement of relationship performance, and can also make employees better complete their work content, so as to achieve the purpose of improving task performance.

\section{CONCLUSION}

This paper studies the relationship among firm training design, communication skills and job performance. The conclusions are as follows:

1) Firm training design has a significant positive impact on job performance.

2) Firm training course design has a significant positive impact on employee communication ability.

3) Employee communication ability has a significant positive impact on job performance.

\section{AUTHORS' CONTRIBUTIONS}

The main theoretical contributions of this paper are as follows: First,previous studies mostly focused on the design of communication training in the medical and nursing industry, lacking universal applicability. This paper starts from multiple industries to explore the effect of communication training design on employees' communication ability and work performance.

Second, in the context of COVID-19's impact and the gradual transformation of enterprise communication mode into online, the importance of communication training course design is explored.

But this paper also has some limitations:Although some findings have been made, the data are old and the analysis of the data is not detailed enough. At the same time, the influence of staff training design on communication ability and work performance is complex, which needs further exploration.

\section{ACKNOWLEDGMENTS}

Imperceptibly, the writing of the thesis is coming to an end. In the process of writing this thesis, there are too many people to thank.

First of all, I would like to thank Professor Fei Wang for his great help in the process of writing this paper. Professor Fei Wang has a rigorous academic attitude and profound academic level. His guidance and help have brought me a lot of inspiration. Because of this, I can successfully complete this paper.

At the same time, I would also like to thank all the teachers and students who have continuously encouraged and helped me in the whole process. It was because of their encouragement that I became more energetic and aroused more interest.

\section{REFERENCES}

[1] Lin Qiu-yu, Song Shao-feng, He Zhen. Discussion on the influence of network on internal communication 
behavior of organizations [J]. Journal of Southwest Jiaotong University (SOCIAL SCIENCE EDITION), 2007 (04): 88-91.

[2] Zhong Ding-guo, Liu Jie. The impact of employee training on job performance from the perspective of employee perception: the mediating role of job engagement $[\mathrm{J}]$. Journal of Xi'an University of technology, 2014,34 (11): 900-905.

[3] Arnold, J., Silvester, J. , Patterson, F. , Robert - son, I. , Cooper , C. , \& Bur nes, B. Work Psychol ogy: Underst anding Human Behaviour in the Workpl ace. 4thed. London: FT/ Pr ent ice Hal 1, 2005: 357, 358, $361,364,375$.

[4] Wang Song-xian . Curriculum design and content development of enterprise training $[\mathrm{J}]$. China Adult Education, 2006 (03): 96-97.

[5] Bernardin, Human Resource Management: The Method of Practice[M].PENG Ji-sheng, Translated. Nanjing: Nanjing University Publishing House, 2009.

[6] Feng Ya-nan. Training and employee performance analysis and suggestions[J]. Modern management science, 2006, 5, 30 .

[7] Warr, P. Psychol ogy at Wor k. 5t h ed. London: Pengui n books, 2002: 160, 166

[8] Spitzberg B H. Interpersonal communication competence[J]. (beverly hills), 1984.

[9] Spitzberg B H. Communication competence: Measures of perceived effectiveness. 1988.

[10] Leslie GR. IDENTITY AND INTERPERSONAL COMPETENCE: A NEW DIRECTION IN FAMILY RESEARCH. By Nelson N. Foote and Leonard S. Cottrell, Jr. Chicago: The University of Chicago Press, 1955.305 pp. \$5.00[J]. Social Forces, 1956(4):389-390.

[11] WANG Zhao-qin. Training methods and effects of improving nurses' communication skills[J]. Journal of nursing management, 2008 (01): 46-47.

[12] Carol Ann Boyer:Communities of practice and the support of core competency knowledge in the information technology consulting firm,A dissertation proposal for PH.D, Capella University, 2003.

[13] Zhang Hui-chen. Performance management: continuous and effective performance communication with employees [J]. China quality, 2004 (07): 7-10.

[14] Boorom M L, Goolsby J R, Ramsey R P . Relational communication traits and their effect on adaptiveness and sales performance[J]. Journal of the Academy of Marketing Science, 1998, 26(1):16.

[15] Li He-ling, Hu Ning-na, Ran Li . Practice and effect analysis of using scenario simulation training to improve nurses' communication ability [J]. Journal of nursing management, 2006 (01): 44-45 + 49.

[16] Liu Xi-yuan. Research on the relationship between emotional intelligence, communication ability and sales performance of sales staff in multinational companies [D]. Central South University, 2008.

[17] CAGRIO. The Effects of Organizational Training on Organizational Commitment[J]. International Journal of Training and Development, 2010,14(4): 309. 